\title{
Detecting Spatial and Temporal Change of NDVI Dynamics in the Mekong River Basin: Relationship with Anthropogenic Effects
}

\author{
Tawatchai Na-U-Dom and Xingguo Mo
}

\begin{abstract}
Beside climate effect on vegetation dynamics, understanding spatial and temporal vegetation response to human effect is also crucial for integrated basin management in the Mekong River Basin (MRB). In this study, Normalized Difference Vegetation Index (NDVI) images and climate data from 1995 to 2004 were downloaded from a Global Inventory Modeling and Mapping Study (GIMMS) and Climate Research Unit Time Series version 3.23 (CRU-TS 3.23). The normalized Human Influence Index (HII), was used as a proxy data for anthropogenic effect, was downloaded from Global Human Footprint Dataset (from 1995 to 2004). The residual NDVI trend analysis (RESTREND) and Kruskal-Wallis one-way analysis and Mann-Whitney $U$ test for paired test were applied for this study. The results showed that the human effect on cropland, in northeast Thailand and the Mekong Delta, mostly improved vegetation greenness. The forest ecosystem in Laos and Myanmar reflected land degradation, which was caused by high anthropogenic activities. Yet savanna and woody savanna, grassland, and mixed forest ecosystems showed more greening in low human activities areas. For a comparison of levels of human effect in different vegetation types, he results showed the evergreen forest ecosystem was the most sensitive with the level of human activities. In addition, the vegetation shown significant decreasing NDVI trend over 10 years (1995 to 2004) in high human activities areas, except for cropland. Human activities helped the cropland to grow.
\end{abstract}

Index Terms-Human activities, Mekong river basin, normalized human influence index, residual trend analysis, vegetation dynamics.

\section{INTRODUCTION}

Analysis of land vegetation response to the disturbance, both climate and human disturbance, is essential element which allows better understanding of the disturbance effect on ecosystems in the changing world [1], [2]. Yet many previous researches mainly focused on climate effect on vegetation dynamics, and found that climate contributors, such as temperature, precipitation, and soil moisture, to vegetation change are important for many regions [3]-[6], which is included the MRB [2] and its sub-basin [7].

The MRB is the longest river in Southeast Asia, and its ecosystem services support around 70 million people and highly diversity of life. However, nowadays, many researchers have focused on the climate effect on vegetation

Manuscript received April 19, 2017; revised September 2, 2017. This work was supported in part by the Civil Service Commission (OCSC), Thailand.

The authors are with the Institute of Geographic Sciences and Natural Resource Research, Chinese Academy of Sciences, and Sino - Danish College, University of Chinese Academy of Sciences, Beijing, China (e-mail: tawatchai_naudom@hotmail.com,moxg@igsnrr.ac.cn). dynamics in the RMB. Na-U-Dom et al. [2] concluded that the vegetation in the MRB showed greening trend during past three decades. Average temperature, minimum temperature and maximum temperature, precipitation, and potential evapotranspiration were illustrated to have increasing temporal trends in all location in the basin. However, the climatic factors driving vegetation dynamics were different depending on vegetation types. In the MRB's sub-basin scale, the Net Primary Production (NPP) in the southeast Lancang river basin response to annual precipitation was more complicated than temperature effect, while the meadow-growing season NPP change strongly correlated with precipitation and temperature variability in the northwestern part of the Lancang river basin [8]. The northeast part of Thailand, the seasonal NDVI pattern of deciduous forest, paddy, and crop field relate to precipitation variability, while the evergreen forest ecosystem shown that temperature was a main contributor that effect its greenness and productivity [7]. However, these publications mainly emphasize on the climate effect on vegetation dynamics. Beside climate effect on vegetation in the MRB, human activities such as land use change, population growth [9], fertilization, irrigation etc. could also impact to NDVI trend [1]. Unfortunately, it is not clear how human activities affect NDVI trend and how their effects evolve over time in the MRB.

In this study, we analyze the spatial and temporal pattern of vegetation dynamics over a decade and reveal their relationship with human factors. The questions are how do the human effect relates to vegetation trend in the basin scale and in different vegetation types.

\section{MATERIALS AND METHODS}

\section{A. Study Area}

The MRB, Fig. 1, is originated at the Qinghai-Tibetan plateau, China, where it flows through six countries, which are China, Myanmar, Laos, Thailand and Vietnam. The basin can be separated into three parts: the upper basin in the Qinghai-Tibetan plateau and Yunnan, China, and the lower basin in Southeast Asia where its outlet point in the South China Sea [10].

The MRB is governed by monsoon climate systems, the northeast (November to early March) and southwest monsoon (May to early October). The mean temperature is topographically vary, but average temperature for a whole basin is around $24{ }^{\circ} \mathrm{C}$. In addition, the accumulative annual precipitation is also topographically changing. It is from 1,000 to $1,500 \mathrm{~mm}$ in Thailand and more than $3,200 \mathrm{~mm}$ in 
Laos; while, in the upper part of basin, it ranges from $600 \mathrm{~mm}$ in the Qinghai-Tibetan plateau to $1,700 \mathrm{~mm}$ in the mountainous region in Yunnan, China [10], [11].

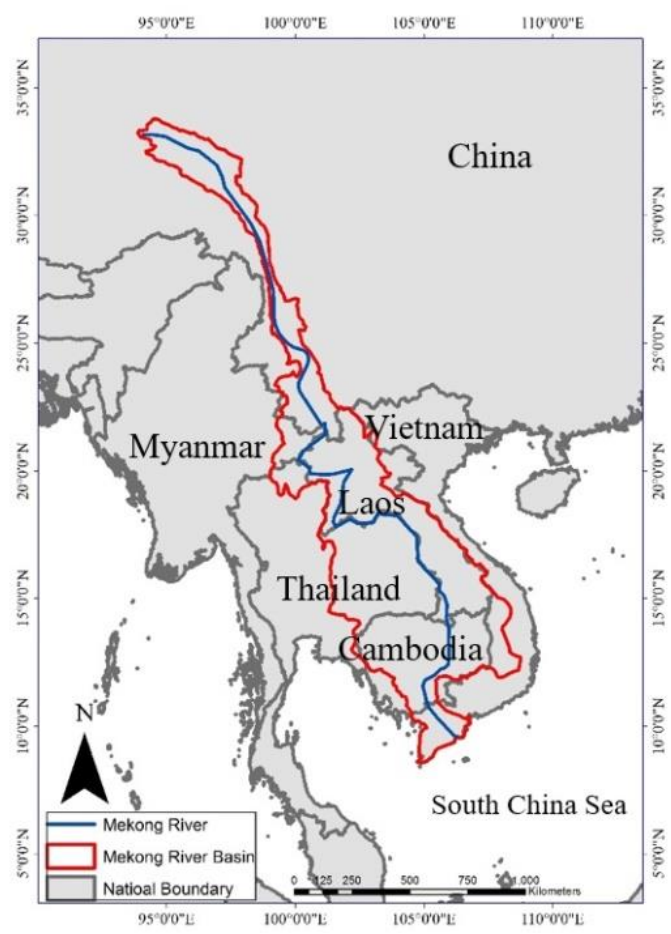

Fig. 1. The location of the study area.

\section{B. Dataset}

In this research, several datasets were used as follow.

1) In this study, biweekly NDVI images from January 1995 to December 2004 were download from GIMMS [12]. The Savitzky-Golay (S-G) filter was applied to avoid the atmospheric contaminants and to deriving and correct value from the NDVI time series [13]. Then, the coordinate system was defined as GCS-WGS 1984, and bi-linear interpolation was used in order to downscale NDVI images' spatial resolution, from 8-km2 to 1-km2. The monthly NDVI dataset were the average of biweekly NDVI images.

2) Monthly average temperature, minimum temperature, maximum temperature, precipitation and potential evapotranspiration (PET) from January 1995 to December 2004 were download from CRU-TS 3.23 with $0.5^{\circ}$ spatial resolution [14]. The bi-linear interpolation was applied to downscale from a $0.5^{\circ}$ spatial resolution to $1 \mathrm{~km} 2$ resolution.

3) HII, a proxy data for anthropogenic effect, was downloaded from Global Human Footprint Dataset (from 1995 to 2004) with 1-km2 spatial resolution. It is a comprehensive index to indicating human effect on the environment. The index ranges from 0 to 100 , with high value representing a high human impact [15]. In this study, the HII value was divided to 2 levels, which were low human activities level, HII < 30, and high human activities level, HII > 30, while no human effect, as representative of no human activities, was estimated by equation (1).

C. Anthropogenic Effect on Vegetation Dynamics Analysis

To access the anthropogenic effect on vegetation dynamic,
HII and predicted NDVI from climatic variables were used to access the residual trend (RESTREND) of NDVI from 1995 to 2004 .

The predicted NDVI (NDVI ${ }_{\text {pred }}$ ) of year $i$ were predicted by multiple linear regression model by using multiple linear regression by using minimum temperature $\left(\mathrm{TMN}_{i}\right)$, maximum temperate $\left(\mathrm{TMX}_{i}\right)$, average temperature $\left(\mathrm{Temp}_{i}\right)$, precipitation $\left(\mathrm{Prec}_{i}\right)$ and Potential evapotranspiration $\left(\mathrm{PET}_{i}\right)$ of year $i$ as the predictors from 1994 to 2005. Then, the residual NDVI $\left(\mathrm{NDVI}_{\text {res }(i)}\right)$ of year $i$ was evaluated from the difference of observed NDVI $\left(\mathrm{NDVI}_{o b s(i)}\right)$ and $\mathrm{NDVI}_{\text {pred(i) }}$. Hence, the equations was calculated to each pixels are showed as equation (1) and (2).

$$
\begin{gathered}
N D V I_{\text {red }(i)}=\alpha+\beta \operatorname{Pemp}_{(i)}+\gamma \operatorname{Prec}_{(i)}+ \\
\operatorname{SPET}_{(i)}+\mu \operatorname{TMN}_{(i)}+\rho T M X_{(i)}+\varepsilon_{(i)} \\
N D V I_{\text {res }(i)}=N D V I_{\text {obs }(i)}-N D V I_{\text {pred }(i)}
\end{gathered}
$$

where $\alpha, \beta, \gamma, \delta, \mu, \rho$ and $\varepsilon$ are multiple linear regression coefficients and residual adjust for each variable and pixel of year $i$.

Then, the level of HII on vegetation dynamics from 1995 to 2004 were used to evaluate and compare with the residual NDVI trend between no human influence low and high human effect (from level of HII), based on different vegetation type using Kruskal-Wallis one-way analysis and Mann-Whitney U test for paired test. This part compares the RESTREND of NDVI from 1995 to 2004 and the levels of HII amount different vegetation. This approach was applied from Mueller et al. [16] and Liu et al. [1].

\section{RESUlts}

\section{A. The Anthropogenic Activities on Vegetation Dynamics}

The RESTREND of NDVI, RESTREND's significance test, the HII, and land cover in the MRB are showed in Fig. 2 and Fig. 3. The human effect on cropland in the northeast of Thailand and the Mekong Delta in Vietnam is high (Fig. 2a), but the human activities mostly improve cropland greenness (Fig. 2b). On the other hand, some part of northeast Thailand illustrated that the human effect promoted land degradation, RESTREND analysis (Fig. 3a and Fig. 3b). The MRB in Laos and Myanmar mostly presented low human activities, but the forest ecosystem in Laos and Myanmar reflected significant land degradation, especially in southern Laos, which was very obvious when compared to another part of Laos, around -0.005 to -0.010 NDVI point / year, (Fig. 3a and Fig. 3b). In parts of Cambodia and Vietnam, which were mostly covered by savanna and woody savanna ecosystem (Fig. 2b), the human activities ranged from low to high, but the human activities mostly promoted vegetation greenness, except for central of Cambodia, which mostly showed a browning trend (Fig. 3a). For the upper part of the basin, it was visibly seen that the mixed forest ecosystem in Yunnan, China, showed rather low human activity, but the result (Fig. 2a and Fig. 3a) illustrated human activities negatively impacted the mixed forest ecosystem. In the Tibetan Plateau, which was covered by grassland, low human activities promoted vegetation greenness in the grassland biome. 


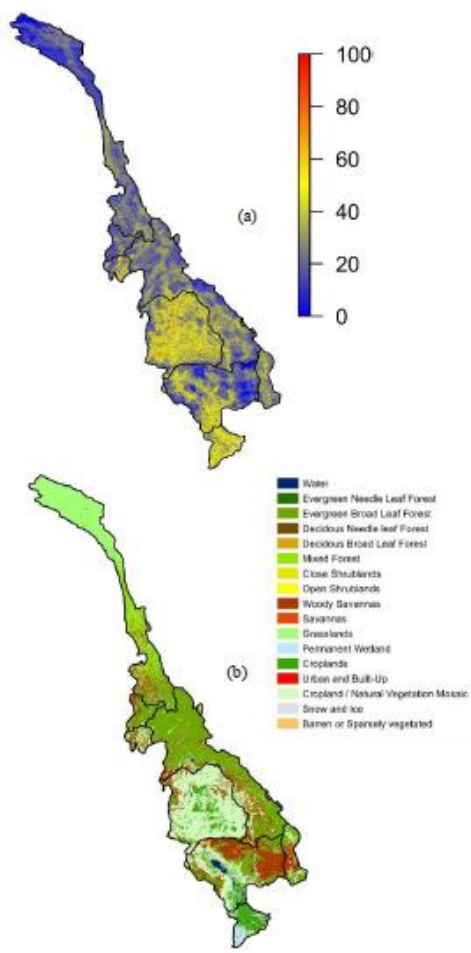

Fig. 2. (a) The spatial distribution of the HII, in which colored bar indicates the degree of human activities, and (b) land cover in MRB, which retrieved from MODIS land cover type product (MCD12Q1) [17].

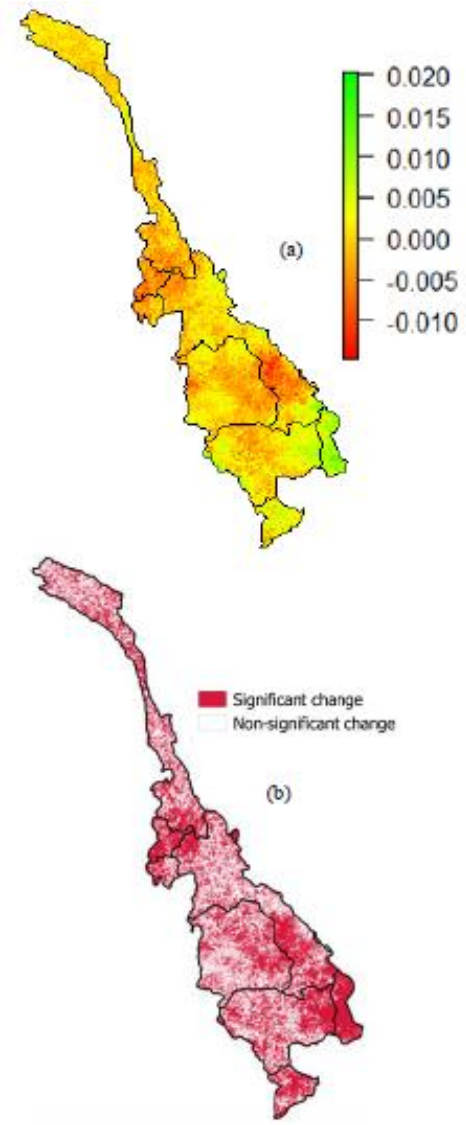

Fig. 3. (a) The spatial RESTREND analysis of NDVI (residual NDVI point / year) from 1995 to 2004 , and (b) the spatial significant map ( $p$-value $<0.05)$ of RESTREND analysis.

\section{B. The Degree of Anthropogenic Activities to Different Vegetation Types}

In this part, the hypothesis is that more intensive human activities (the level of HII), either positive or negative effect, could lead to change in vegetation dynamics. Different vegetation are conducted at the regional scale for the reason that anthropogenic impact is relative to its political, economic and social status. Hence, the analysis of this part is conducted in the regional scale [16].
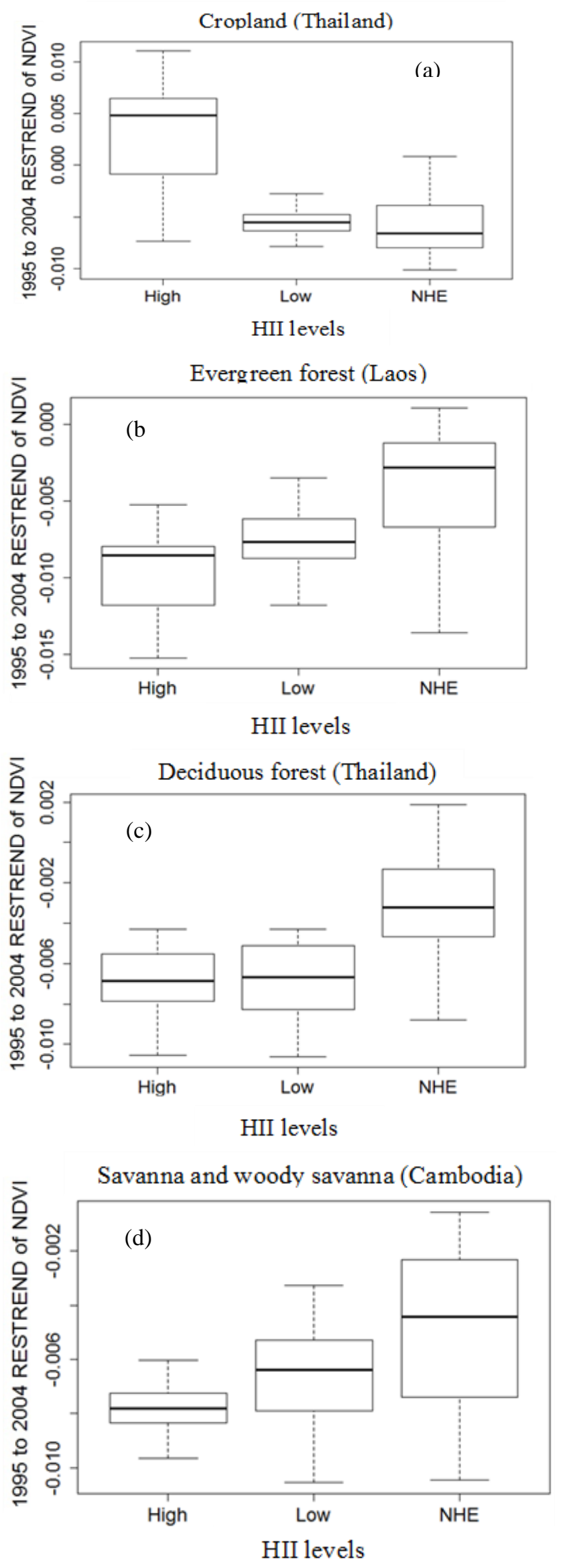

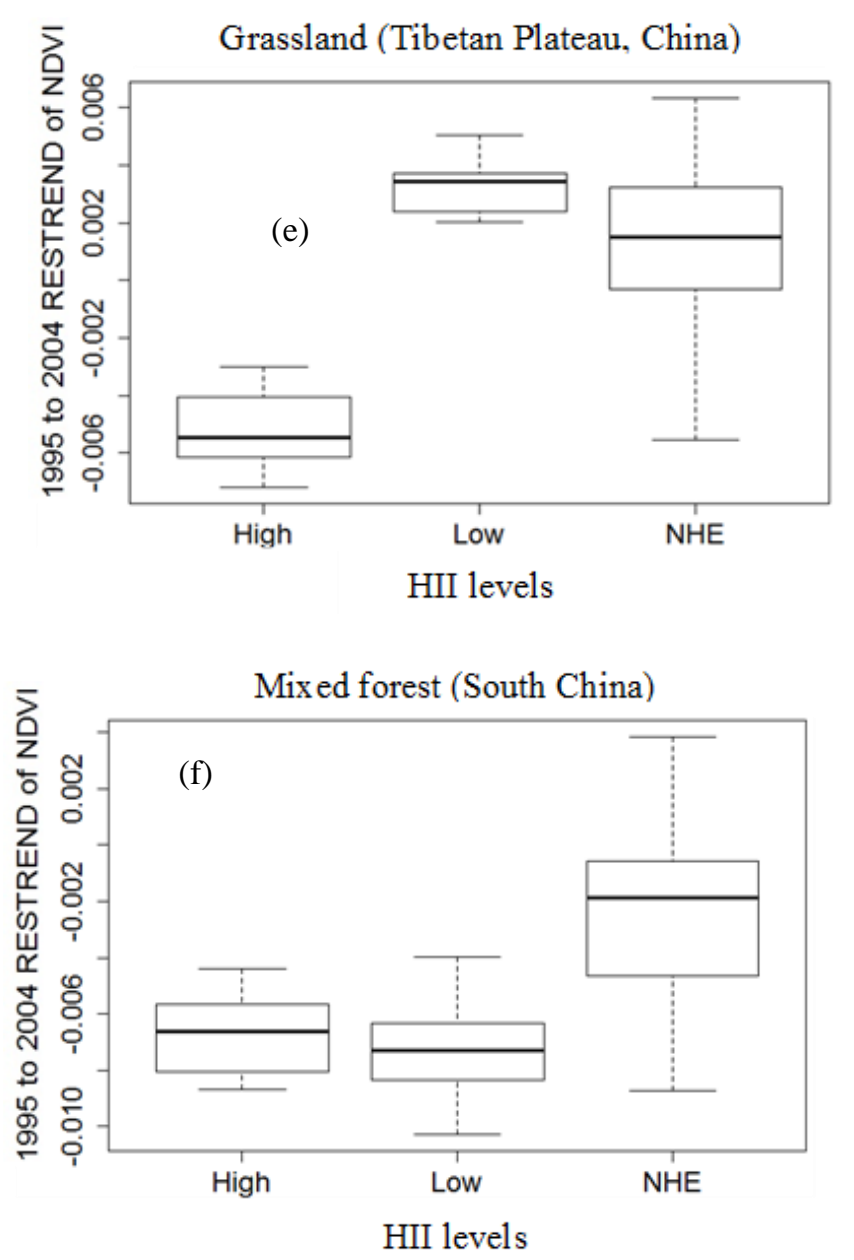

Key: NHE $=$ No human effect, Low $=$ Low human impact, and High $=$ High human impact.

Fig. 4. The boxplot of the human effect on vegetation trend from 1995 to 2004 in different vegetation types and different levels of human effect.

TABle I: Result from ManN-Whitney U Test for Paired Test in DIFFERENCE LEVEL OF HII AND NHE, WhILE S (NS) REPRESENT (NON) SigNiFICANCE AT $95 \%$ CONFIDENCE LEVEL OF STATISTICAL ANALYSIS

\begin{tabular}{cccc}
\hline \hline & \multicolumn{3}{c}{ Degree of human impact } \\
\cline { 2 - 4 } & Low v. High & Low v. NHE & High v. NHE \\
\hline Cropland & $s$ & $n s$ & $s$ \\
Evergreen forest & $s$ & $s$ & $s$ \\
Deciduous forest & $n s$ & $s$ & $s$ \\
Savanna and & $s$ & $n s$ & $s$ \\
woody savanna & $s$ & $n s$ & $s$ \\
Grassland & $s$ & $s$ & $s$ \\
Mixed forest & $n s$ &
\end{tabular}

The results from the boxplot (Fig. 4) and Mann-Whitney $\mathrm{U}$ test (Table I) showed that cropland was significantly different of RESTREND in different levels of human activities. It was clearly seen that human impact improved the cropland production (Fig. 4a). Moreover, the level of HII was significantly different between NHE high human activities (Table I), but the vegetation did not show statistical difference from NHE and low human activities condition.

The evergreen forest was very sensitive to the degree of human activities, even low human activity; while the evergreen forest ecosystem showed a browning trend (Fig. $4 b)$. Moreover, the Mann-Whitney U test confirmed that RESTREND from low human activities condition was significantly different from either NHE or high human activities (Table I). Deciduous forest showed that either low or high level of human activities could induce a browning trend (Fig. 4c) but it was non-significantly different between low and high human activities to RESTREND of NDVI (Table I). Savanna and woody savanna biome and grassland showed no difference between RESTREND of low and no human activities (Table I). However, human activities affected savanna and woody savanna ecosystem, and were important for savanna and woody savanna degradation (Fig. 4d). Yet low human activities promoted grassland productivity and the ecosystem showed a degradation (browning) trend on the high level of anthropogenic effect (Fig. 4e). The mixed forest ecosystem showed the same response to anthropogenic level as the deciduous forest ecosystem, but a high level of human impact drove the greening trend of RESTREND (Fig. 4f).

\section{DisCUSSION AND CONCLUSION}

The effect of human activities during last 30 years was analyzed using the RESTREND analysis, in which a degree of heterogeneity is present in the relationship between human activities and vegetation cover [6]. Furthermore, this study also compared the result of spatial distribution of RESTREND and its significant test with HII. Rowcroft [9] summarized the human activities in the MRB. The authors concluded human activities lead to the land use change, which initiates huge pressure on natural resources. The main human actives in the MRB lead to land use change, population growth, shifting cultivation, and road building. In addition, changed land use in the upstream intuitively knows that had a potential effect to the livelihoods of population in the downstream by changing critical watershed function.

In this research, the residual slopes were mostly positive in the basin scale, especially in parts of Vietnam and east of Cambodia. For the local scale. In the grassland ecosystem, in the Tibetan Plateau, the main human activities are grazing and human-induced land cover change, which mostly showed low human activities in spatial scale with the positive RESTREND. It could be concluded that human activities can promote grassland growth. Chen et al. [18] also found this and concluded the actual grassland NPP changed from $20.16 \%$ to $42.98 \%$ by anthropogenic activities in last 10 years over the Tibetan Plateau. Although human activities, such as grazing, could promote vegetation productivities, Du et al. [19] suggested that land degradation by over grazing is the main human problem in the Tibetan Plateau [20], affecting the climate change by recuing the ET process and leading to significant higher temperature in the grassland ecosystem. Hence, the local climate warming can promote the grassland growth, but it also leads to land degradation by affecting the higher water deficit (meaning, ET), which essentially degraded the grassland ecosystem [19]. In Yunnan province, China, the mixed forest ecosystem showed significant positive residual trend that could be interpreted as human activities, with low HII level promoting the vegetation greenness in this ecosystem. Geng [21] also confirmed that reforestation and forest protection have been implement in Yunnan province.

The area with significant negative slope was in the lower part of basin, which is in south Laos and Cambodia. Even though some reforestation projects have been implemented in some parts of the lower basin, such as in Vietnam [22], the 
study of forest losses between 1993 and 1997 found that the lower MRB as a whole lost close to 500,000 ha in four years (equivalent to $0.5 \%$ of the annual deforestation rate) [9]. In addition, the lower MRB faced hydrological drought in 1992 and 1998 [10]. The drought impact influenced vegetation growth and significantly decreased NDVI values. The negative effects caused by extreme events have counterbalanced the positive effect of newly developed reforestation and management of the ecological restoration program [6]. In contrast, cropland greenness is promoted by population growth [9], which can lead to technological and irrigational improvement, facilitate agriculture development, and the provision of labor for agricultural development.

Lastly, this research concluded the following; 1) For the human influence on vegetation dynamics, the human effect on northeast Thailand and the Mekong Delta mostly improved vegetation greenness. The forest ecosystem in Laos and Myanmar reflected land degradation, which was caused by high anthropogenic activities, especially in south Laos. Yet savanna and woody savanna, grassland, and mixed forest ecosystems showed more greening in low human activities areas. 2) A comparison of RESTREND in low and high human activities areas and predicted NDVI trend to capture the level of human activities in different vegetation were evaluated. The results showed the evergreen forest ecosystem was the most sensitive with the level of human activities. Even though low human activities were applied in the forest area, the forest NDVI trend significantly decreased and more significantly decreased when reached to the high level of human activities. In addition, the vegetation shown significant decreasing NDVI trend over 10 years (1995 to 2004 ) in high human activities areas, except for cropland. Human activities helped the cropland to grow.

\section{REFERENCES}

[1] Y. Liu, Y. Li, S. Li et al., "Spatial and temporal patterns of global NDVI trends: Correlations with climate and human factors," Remote Sensing, vol. 7, pp. 13233-13250, 2015.

[2] T. Na-U-Dom, X. Mo, and M. Garcia, "Assessing the climate effects on vegetation dynamics in the Mekong river basin," Environments, vol. 4, 2017.

[3] S. Chamaille-Jammes, H. Fritz, and F. Murindagomo, "Spatial patterns of the NDVI-rainfall relationship at the seasonal and interannual time scales in an African savanna," International Journal of Remote Sensing, vol. 2, pp. 5185-5200, 2006.

[4] Z. Li and X. Guo, "Detecting climate effects on vegetation in northern mixed prairie using NOAA AVHRR 1-km time-series NDVI data," Remote Sensing, vol. 4, pp. 120-134, 2012.

[5] X. W. Chuai, X. J. Huang, and W. J. Wang, "NDVI, temperature and precipitation changes and their relationship with different vegetation types during 1998-2007 in inner Mongolia, China," International Journal of Climatology, vol. 33, pp. 1696-1706, 2013.

[6] H. Wang, A. Chen, Q. Wang et al., "Drought dynamics and impacts on vegetation in China from 1982 to 2011," Ecological Engineering, vol. 75, pp. 303-307, 2015.

[7] W. Thavorntam and N. Tantemsapya, "Vegetation greenness modeling in response to climate change for Northeast Thailand," Journal of Geographical Sciences, vol. 23, pp. 1052-1068, 2013.

[8] C. Huang, Y. Li, G. Liu, H. Zhang et al., "Recent climate variability and its impact on precipitation, temperature and vegetation dynamics in the Lancang River headwater area of China," International of Remote Sensing, vol. 35, pp. 2822-2834, 2014.
[9] P. Rowcroft, "Frontiers of change: The Reasons behind Land-Use Change in the Mekong Basin," Ambio, vol. 37, pp. 213-218, 2008.

[10] Mekong River Commission, Overview of the Hydrology of the Mekong Basin; Vientiane: Red Plough International Co. Ltd, 2005, ch 3.

[11] G. Kite, "Modelling the Mekong: Hydrological simulation for environmental impact studies," Journal of Hydrology, vol. 335, pp. $1-13,2001$.

[12] C. J. Tucker, J. E. Pinzon, M. E. Brown et al., "An extended AVHRR 8-km NDVI data set compatible with MODIS and SPOT vegetation NDVI data," International Journal of Remote Sensing, vol. 26, pp. 4485-4498, 2005.

[13] J. Chen, P. Jönsson, M. Tamura et al., "A simple methods for reconstructing a high-quality NDVI time series data set based on the Savitzky- Golay filter," Remote Sensing of Environment, vol. 91, pp. 332-344, 2004.

[14] I. Harris, P. D. Jones, T. J. Osborn et al., "Update high-resolution grids of monthly climatic observation - the CRU TS3.10 dataset," International Journal of Climatology, vol. 34, pp. 623-642, 2013.

[15] Wildlife Conservation Society and Center for International Earth Science Information Network (WCS - CIESIN) - Columbia University. (2005). Last of the Wild Project, Version 2: Global Human Footprint Dataset (Geographic). Palisades, NY: NASA Socioeconomic Data and Applications Center (SEDAC), 2005.

[16] T. Mueller, G. Dressler, and C. J. Tucker, "Human land-use practices lead to global long-term increases in photosynthetic capacity," Remote Sensing, vol. 6, 2014.

[17] M. A. Friedl, D. Sulla-Menashe, B. Tan et al., "MODIS collection 5 global land cover: Algorithm refinements and characterization of new data set," Remote Sensing of Environment, vol. 114, pp. 168-185, 2010.

[18] B. Chen, X. Zhang, J. Zhang et al., "The impact of climate change and anthropogenic activities on alpine grassland over the Qinghai-Tibet Plateau," Agricultural and Forest Meteorology, vol. 189-190, pp. 11-18, 2014.

[19] M. Du, S. Kawashima, and S. Yonemura, "Mutual influence between human activities and climate change in the Tibetan Plateau during recent years," Global and Planetary Change, vol. 41, pp. 241-249, 2004.

[20] L. Zhu and B. Li, "Mountain genecology and sustainable development of the Tibetan plateau," Dordrecht: Kluwer Academic Publishing, pp 203-222, 2000.

[21] C. Geng, "Problems and suggestions of afforestation projects of Yunnan province," Forest Inventory and Planning, vol. 28, pp. 45-51, 2003.

[22] P. Meyfroidt and E. F. Lambin, "Forest transition in Vietnam and its environmental impacts," Global Change Biology, vol. 14, pp. 1319-1336, 2008.

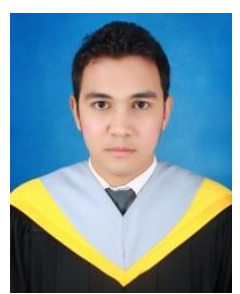

Tawatchai Na-U-Dom was born in Thailand. He received his B.Sc. in aquatic science in 2010 from Burapha University, Thailand. Now, he is studying his M.Sc. at the Institute of Geographic Sciences and Natural Resource Research, Chinese Academy of Sciences, and Sino-Danish College, University of Chinese Academy of Sciences, Beijing, China. His current research interests are in the area of climate and human effects on ecosystem response and the ecosystem stability and resistance on extreme weather events.

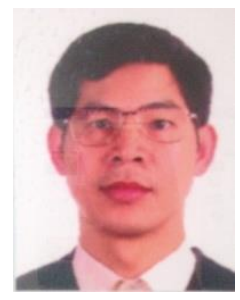

Xingguo Mo is a professor of hydrology at the Key Laboratory of Water Cycles and Related Land Surface Processes, Institute of Geographical Sciences and Natural Resources Research, Chinese Academy of Sciences. He holds a Ph.D. in physical geography (1993) from Institute of Geography, Chinese Academy of Science. His researches mainly focus on climate and eco-hydrology, including: key processes and the mechanism of energy and mass cycle on and across the interfaces among soil-vegetation-atmosphere transfer systems, integrated modelling of climate and eco-hydrological processes, the spatial variation pattern and temporal variation tendency of climate and eco-hydrological elements and The response mechanism of eco-hydrological processes to climate change and environmental change and its adaptation and control. 